\title{
Estimation of L-Dopa from Mucuna pruriens LinN and Formulations Containing M. pruriens by HPTLC Method
}

\author{
Ketan Pravinbhai Modi, ${ }^{a}$ Natvarlal Manilal Patel,${ }^{a}$ and Ramesh Kishorilal Goyal ${ }^{*, b}$ \\ ${ }^{a}$ Department of Pharmacology, Shri B. M. Shah College of Pharmaceutical Education \& Research, College Campus; \\ Modasa-383315, India: and ${ }^{b}$ Department of Pharmacology, L. M. College of Pharmacy; Navarangpura, Ahmedabad- \\ 380009, India. Received February 10, 2007; accepted October 25, 2007
}

\begin{abstract}
A selective, precise, and accurate high-performance thin-layer chromatographic (HPTLC) method has been developed for the analysis of L-dopa in Mucuna pruriens seed extract and its formulations. The method involves densitometric evaluation of L-dopa after resolving it by HPTLC on silica gel plates with $\boldsymbol{n}$-butanol-acetic acidwater $(4.0+1.0+1.0, \mathrm{v} / \mathrm{v})$ as the mobile phase. Densitometric analysis of L-dopa was carried out in the absorbance mode at $280 \mathrm{~nm}$. The relationship between the concentration of L-dopa and corresponding peak areas was found to be linear in the range of 100 to $1200 \mathrm{ng} / \mathrm{spot}$. The method was validated for precision (inter and intraday), repeatability, and accuracy. Mean recovery was $100.30 \%$. The relative standard deviation (RSD) values of the precision were found to be in the range $0.64-1.52 \%$. In conclusion, the proposed TLC method was found to be precise, specific and accurate and can be used for identification and quantitative determination of L-dopa in herbal extract and its formulations.
\end{abstract}

Key words Mucuna pruriens; L-dopa; HPTLC

Indigenous herbs are used as remedies against various diseases in the traditional system of medicine or in ethnomedicinal practices. For the past few decades compounds from natural sources have been gaining importance because of the vast chemical diversity that they offer. This has led to phenomenal increase in the demand for the herbal medicine in the last two decades and a need has been felt for ensuring the quality, safety and efficacy of the herbal drugs. Phytochemical evaluation is one of the tools for the quality assessment, which includes preliminary phytochemical screening, chemoprofiling and marker compound analysis using modern analytical techniques. In the last two decades high-performance thin-layer chromatography (HPTLC) has emerged as an important tool for the qualitative, semi-quantitative and quantitative phytochemical analysis of herbal drugs and formulations. This includes developing TLC fingerprint profiles and estimation of chemical markers and biomarkers. ${ }^{1-3)}$ The major advantage of HPTLC is that several samples can be analyzed simultaneously using a small quantity of mobile phase.

Mucuna pruriens LinN (Leguminosae), commonly known as "the cowhage" or "velvet" bean; and "atmagupta" in India, is a climbing legume endemic in India and in other parts of the tropics including Central and South America. In Ayurvedic system of medicine, M. pruriens was used for the management of male infertility, nervous disorders and also as an aphrodisiac. ${ }^{4)}$ Its different preparations from the seeds are also used for the management of ageing, rheumatoid arthritis, diabetes, male infertility and nervous disorders. ${ }^{5)}$ Other parts of the plants are also medicinal used for various ailments, e.g., trichomes of pods are used for anthelmintics and decoction of root in delirium. Leaves are useful in ulcers, inflammation, cephalagia and general debility. M. pruriens seed powder contains high amount of L-dopa, which is a neurotransmitter precursor and effective remedy for the relief in parkinson's disease. $\left.{ }^{6}\right) \mathrm{M}$. pruriens seed in addition to levodopa, contains tryptamine, 5-hydroxytryptamine (5-HT), mucunine, mucunadine, prurienine and prurieninine. ${ }^{7,8)}$ It is also rich in fatty content. ${ }^{9)}$
The British Pharmacopoeia (B.P.) describes a non-aqueous titration for the determination of L-dopa. ${ }^{10)}$ The United States Pharmacopoeia (U.S.P.) recommends a non-aqueous titrimetric procedure with potentiometric end point determination of L-dopa and extractive procedure followed by UV assay for its determination in formulations. ${ }^{11)}$ Parikh et al. ${ }^{12)}$ described high performance liquid chromatography method for estimation of L-dopa in plant. Siddhuraju et al. ${ }^{13)}$ reported a rapid reversed-phase high performance liquid chromatographic method for the quantification of L-dopa, nonmethylated and methylated tetrahydroisoquinoline compounds from Mucuna beans. Recently, quantitative estimation of L-dopa in tablets has been reported by high performance thin layer chromatography method. ${ }^{14)}$ We report here a simple, specific and accurate method for the estimation of Ldopa, from the seed of $M$. pruriens. L-dopa content was also estimated from two marketed herbal formulations containing M. pruriens as one of the ingredients.

\section{Experimental}

Materials Standard L-dopa was a gift sample from Torrent Research Centre, Ahmedabad, India. All the chemicals used in the experiments are of analytical grade.

Preparation of Extract The seeds of M. pruriens were purchased from United Chemicals and Allied Products, Kolkata, India. It was authenticated by Dr. B. C. Patel, Botany Department, Modasa, India. A voucher specimen was retained in our laboratory for further reference. Seeds were dried in shade and powdered in a mechanical grinder. The powder of $M$. pruriens seeds was initially defatted with petroleum ether $\left(60-80^{\circ} \mathrm{C}\right)$ then aqueous extract was prepared by cold maceration method. After $7 \mathrm{~d}$, the extract was filtered using Whatman filter paper (No. 1) and then concentrated in vacuum and dried.

HPTLC Instrument The samples were spotted in the form of bands with a Camag microlitre syringe on a precoated silica gel plates $60 \mathrm{~F}_{254}$ $(10 \mathrm{~cm} \times 10 \mathrm{~cm}$ with $0.2 \mathrm{~mm}$ thickness, E. Merck, Darmstadt, Germany) using a Camag Linomat V Automatic Sample Spotter (Muttenz, Switzerland). The plates were prewashed by methanol and activated at $60^{\circ} \mathrm{C}$ for $5 \mathrm{~min}$ prior to chromatography. The plate was developed in a solvent system $(6.0 \mathrm{ml})$ of $n$-butanol-acetic acid-water $(4.0: 1.0: 1.0)$ in a CAMAG glass twin-through chamber $(10 \times 10 \mathrm{~cm})$ previously saturated with the solvent for $30 \mathrm{~min}$ (temperature $25 \pm 2{ }^{\circ} \mathrm{C}$, relative humidity $40 \%$ ). The development distance was $8 \mathrm{~cm}$. Subsequent to the scanning, TLC plates were air dried and scanning was performed on a Camag TLC scanner III in absorbance mode at $280 \mathrm{~nm}$ and operated by WinCats software 4.03 version. Evaluation 
was via peak areas with linear regression.

Calibration Curve of Standard L-Dopa A stock solution of L-dopa $(1000 \mu \mathrm{g} / \mathrm{ml})$ was prepared by dissolving an accurately weighed $10 \mathrm{mg}$ of Ldopa standard in $5 \mathrm{ml}$ of anhydrous formic acid and volume was made up to $10 \mathrm{ml}$ with methanol in a volumetric flask. Standard working solutions were prepared by diluting stock solution with methanol in the concentration range $10-120 \mu \mathrm{g} / \mathrm{ml}$. Ten microliters from each standard solution was spotted on the TLC plate to obtain final concentration range of $100-1200 \mathrm{ng} / \mathrm{spot}$. Each concentration was spotted six times on the TLC plate.

Estimation of L-Dopa in Herbal Extract To determine the content of L-dopa in herbal extracts, an accurately weighed $100 \mathrm{mg}$ of dry aqueous extract was transferred into $10 \mathrm{ml}$ volumetric flask and $5 \mathrm{ml}$ of anhydrous formic acid was added, sonicated for $10 \mathrm{~min}$ and volume was made up to $10 \mathrm{ml}$ with methanol. The extract was filtered on a Whatman no. 1 filter paper, from which $1.0 \mathrm{ml}$ of the solution was diluted to $10 \mathrm{ml}$ with methanol in volumetric flask. An aliquot of sample $10 \mu \mathrm{l}$ was applied on the TLC plate. The analysis was repeated for six times.

Estimation of L-Dopa in Marketed Herbal Formulations To determine the content of L-dopa in market formulations, an accurately weighed $100 \mathrm{mg}$ of powder was transferred into $10 \mathrm{ml}$ volumetric flask and $5 \mathrm{ml}$ of anhydrous formic acid was added, sonicated for $10 \mathrm{~min}$ and volume was made up to $10 \mathrm{ml}$ with methanol. The extract was filtered on a Whatman no. 1 filter paper, from that $1.0 \mathrm{ml}$ of the solution was diluted to $10 \mathrm{ml}$ with methanol in volumetric flask. An aliquot of sample $20 \mu \mathrm{l}$ was applied on the TLC plate. The analysis was repeated for six times.

\section{Results and Discussion}

The composition of the mobile phase for TLC was optimized by testing different solvent mixtures of varying polarity. The best results were obtained using $n$-butanol-acetic acid-water $(4.0: 1.0: 1.0)$. The selected mobile phase showed good resolution (Fig. 1). The compound with $R f$ value 0.39 was identified as L-dopa. In the reported HPLC method by Siddhuraju et al. ${ }^{13)}$ the gradient elution technique was used and mobile phase was consisted of water, methanol, phosphoric acid and methanol and the $\mathrm{pH}$ was adjusted to 2.0. Thus as compared to the reported method, our proposed method requires simple solvent system to separate the Ldopa from the extract. The peak purity was assessed by comparison of overlay spectra of standard L-dopa and $M$. pruriens seed extract at peak apex and peak base which confirm the method was selective (Fig. 2).

Method Validation The HPTLC method was validated in terms of precision, accuracy and repeatability (Table 1). The method was found to be specific as it well resolved Ldopa with $R f$ value of 0.39 , in the presence of other components in the sample. Linearity was evaluated by determining eight standard working solutions containing $10-120 \mu \mathrm{g} / \mathrm{ml}$ of L-dopa. Peak area and concentrations were subjected to least square linear regression analysis to calculate the calibration equation and correlation co-efficient. Linearity was found over concentration range $100-1200 \mathrm{ng} / \mathrm{spot}$ with a correlation coefficient $(r) 0.99$. The linearity of calibration graph and adherence of the system to Beer's law was validated by high value correlation co-efficient. In the reported HPLC method by Siddharaju and Becker ${ }^{13}$ ) linearity was in the range of $2-100 \mu \mathrm{g} / \mathrm{ml}$ while in our method the linearity range was $10-120 \mu \mathrm{g} / \mathrm{ml}$. Hence it is comparable with the reported method. The instrumental precision was studied by repeated scanning of the same spot for seven times and \% coefficient of variation (CV) was found to be 0.95 . Repeatability of the method was tested by analyzing the standard so-

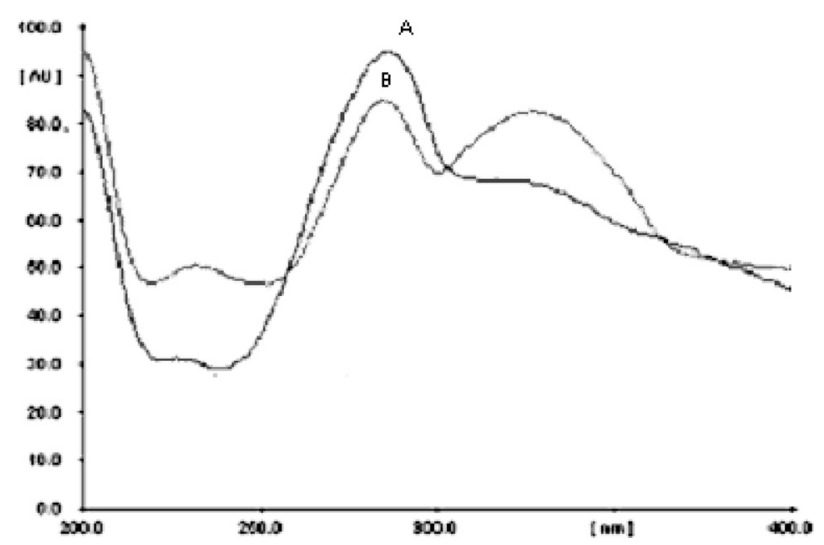

Fig. 2. Overlay Spectra of (A) Standard L-Dopa (B) a Typical Seed Extract of Mucuna pruriens

Table 1. Method Validation Parameters for the Estimation of L-Dopa by HPTLC Method

\begin{tabular}{clc}
\hline \hline Serial No. & \multicolumn{1}{c}{ Parameter } & Result \\
\hline 1 & Instrumental precision $(\mathrm{CV}, \%)(n=7)$ & 0.95 \\
2 & Repeatability $(\mathrm{CV}, \%)(n=5)$ & 0.79 \\
4 & Limit of quantification $(\mathrm{ng} / \mathrm{spot})$ & 100 \\
5 & Specificity & Specific \\
6 & Linearity (correlation coefficient) & 0.993 \\
7 & Range (ng/spot) & $100-1200$ \\
\hline
\end{tabular}
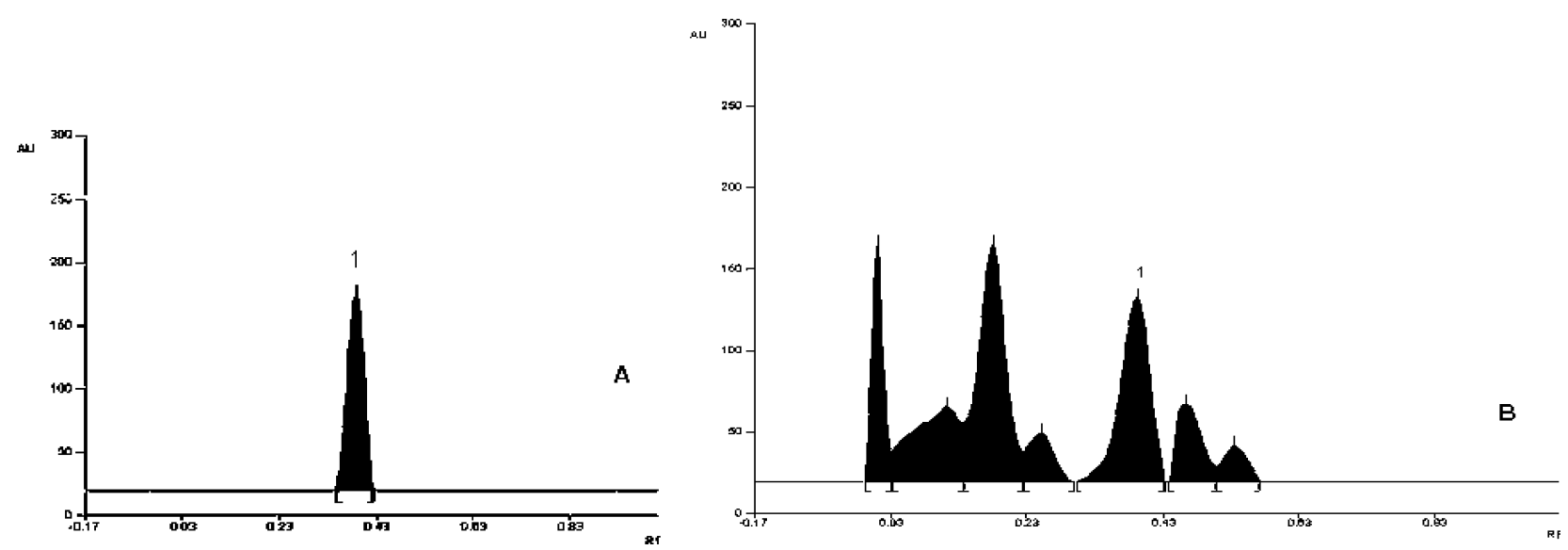

Fig. 1. HPTLC Chromatograms of (A) Standard L-Dopa (B) a Typical Seed Extract of Mucuna pruriens Key to peak identity: 1, L-dopa. 
Table 2. Intra- and Inter-Day Precision of HPTLC Method

\begin{tabular}{ccc}
\hline \hline $\begin{array}{c}\text { Concentration } \\
\text { (ng/spot) }\end{array}$ & $\begin{array}{c}\text { Intra-day precision } \\
(\mathrm{RSD}, \%, n=6)\end{array}$ & $\begin{array}{c}\text { Inter-day precision } \\
(\mathrm{RSD}, \%, n=6)\end{array}$ \\
\hline 200 & 0.78 & 0.70 \\
400 & 0.92 & 1.52 \\
600 & 0.64 & 1.38 \\
800 & 0.71 & 0.98 \\
\hline
\end{tabular}

Table 3. Recovery Study of L-Dopa by HPTLC Method

\begin{tabular}{cccrr}
\hline \hline $\begin{array}{c}\text { Sample } \\
\text { No. }\end{array}$ & $\begin{array}{c}\text { Amount of } \\
\text { L-dopa present } \\
\text { in powder of } \\
\begin{array}{c}\text { M. pruriens } \\
(\mathrm{mg})\end{array}\end{array}$ & $\begin{array}{c}\text { Amount of } \\
\text { L-dopa } \\
\text { L-dopa added } \\
(\mathrm{mg})\end{array}$ & $\begin{array}{c}\text { Amount of } \\
\text { L-dopa found } \\
\text { in the mixture } \\
(\mathrm{mg})\end{array}$ & \% Recovery ${ }^{a)}$ \\
\hline 1 & 5.6 & 1.4 & $7.04 \pm 0.036$ & $100.57 \pm 0.029$ \\
2 & 5.6 & 2.8 & $8.33 \pm 0.051$ & $99.17 \pm 0.005$ \\
3 & 5.6 & 4.2 & $9.68 \pm 0.045$ & $98.78 \pm 0.022$ \\
4 & 5.6 & 5.6 & $11.51 \pm 0.069$ & $102.67 \pm 0.032$ \\
\hline
\end{tabular}

a) Mean \pm S.D., $n=6$.

lution $(200 \mathrm{ng} / \mathrm{spot})$ for five times $(\% \mathrm{CV}=0.79)$.

The reproducibility of the method was determined by different analysts using the samples from the same homogeneous batch and repeatability was determined by intra-day and inter-day precision, expressed in terms of percent relative standard deviation (RSD\%) or CV. Six determinations were carried out on the same sample, on the same day for intraday and over two consecutive days for inter-day precision on four samples. The values of $\mathrm{RSD} \%$ of intra and inter-day were found between $0.64-0.92 \%$ and $0.70-1.52 \%$, respectively (Table 2). No significant difference was observed in the analysis of L-dopa in three different samples. The RSD\% of the reproducibility of the method was found to be $<2 \%$.

The accuracy of the method was determined from recovery studies. A known but varying amount of standards from Ldopa was added to the pre analyzed sample and analyzed according to the procedure. The results are reported in Table 3. The recovery was found to be $100.57 \%, 99.17 \%, 98.78 \%$ and $102.67 \%$ at the four levels respectively and the average recovery was $100.30 \%$.
Table 4. Percentage of L-Dopa in Samples Analyzed

\begin{tabular}{clc}
\hline \hline Sample No. & Sample name & \% of L-dopa ${ }^{a)}$ \\
\hline 1 & Mucuna pruriens & $5.6 \pm 0.430$ \\
2 & Formulation 1 & $4.3 \pm 0.006$ \\
3 & Formulation 2 & $3.8 \pm 0.017$ \\
\hline
\end{tabular}

a) Mean \pm S.D., $n=3$.

Application of the Method The proposed method was applied for the estimation of L-dopa content in extract of $M$. pruriens and its formulations. The obtained results are depicted in Table 4.

\section{Conclusions}

The developed HPTLC method is simple, specific and accurate. Statistical analysis proves that the method is reproducible and selective. This method can be used for the quantitative determination of L-dopa in herbal extract and its formulations.

\section{References}

1) Ravishankara M. N., Shrivastava N., Jayathirthaa M. G., Padh H., Rajani M., J. Chromatogr. B, 744, 257-262 (2000).

2) Rajani M., Shrivastava N., Ravishankara M. N., Pharm. Biol., 38, 204-209 (2000)

3) Ravishankara M. N., Shrivastava N., Padh H., Rajani M., J. Planar Chromatogr., 14, 34-41 (2001).

4) Pandey G. S., Chunekar K. C., "Bhavprakash Nighantu Chaukhamba vidhyabavan," Varanasi, India, 1996, pp. 357-359.

5) Anonymous, "The Wealth of India," PID, CSIR, New Delhi, 1962, pp. $439-444$.

6) Manyam B. V., Parikh K. M., Ann. Neurosci., 9, 40-46 (2002).

7) Ghosal S., Singh S., Bhattachrya S. K., Planta Med., 19, 279-284 (1970).

8) Mehta J. C., Majumdar D. N., Ind. J. Pharm., 6, 92 -94 (1994).

9) Panikkar K. R., Majella V. L., Pillai P. M., Planta Med., 53, 503-507 (1987).

10) "British Pharmacopoeia," Vol. I and II, HMSO Publication Centre, London, 1980, p. 254, 535, 781 .

11) "The United State Pharmacopoeia, XXI, 21st Revision," The US Pharmaceutical Convention Inc., Rockville, 1987, pp. 585-586.

12) Parikh K. M., Doshi V. J., Sawant S. V., Salunkhe U. B., Indian Drugs, 27, 353-356 (1990)

13) Siddhuraju P., Becker K., Food Chem., 72, 389-394 (2001).

14) Mennickent S., Nail M., Vega M., Dediego M., J. Sep. Sci., 30, $1893-$ 1898 (2007). 